\title{
Together We Make a Difference
}

\author{
Kiran K. Turaga, MD, MPH ${ }^{1}$, T. Clark Gamblin, MD, MS, MBA ${ }^{2}$, H. Richard Alexander, MD, PhD $^{3}$, \\ Robert Edwards, $\mathrm{MD}^{4}$, and David L. Bartlett, $\mathrm{MD}^{5}$
}

${ }^{1}$ Department of Surgery, University of Chicago, Chicago, IL; ${ }^{2}$ Department of Surgery, Medical College of Wisconsin, Milwaukee, WI; ${ }^{3}$ Department of Surgery, Rutgers Robert Wood Johnson Medical School, Piscataway Township, NJ; ${ }^{4}$ Department of Obstetrics/Gynecology, University of Pittsburgh, Pittsburgh, PA; ${ }^{5}$ Department of Surgery, University of Pittsburgh, Pittsburgh, PA

The Regional Cancer Therapies article series marks the fourth anniversary of the relationship between the Society of Surgical Oncology (SSO) and the International Symposium of Regional Therapies via the Annals of Surgical Oncology. The remarkable success and alignment has led to a closer association between the two groups, with a resulting joint SSO-International Symposium of Regional Therapies at Jacksonville in 2018. We celebrate this association and the remarkable advances in regional therapies with this very special supplement.

Last year was a key year in cancer care and the use of regional therapies. Several ongoing clinical trials have accrued successfully, and we look forward to the results of the recent few U.S. and International trials examining the role of regional therapies in peritoneal metastases. The field of hepatic and limb regional therapies have been punctuated with advances in regional therapies including immunotherapy, oncolytic virus therapy and catheter-based therapies. This year saw the National Comprehensive Cancer Network (NCCN) guidelines and the European Society for Medical Oncology (ESMO) guidelines endorse the use of intraperitoneal chemotherapy for colorectal metastases. Additionally, the 8th-edition American Joint Committee on Cancer (AJCC)/Union for International Cancer Control (UICC) classification now identifies patients with peritoneal disease (M1c). This supplement

(C) Society of Surgical Oncology 2018

First Received: 5 January 2018;

Published Online: 15 May 2018

K. K. Turaga, MD, MPH

e-mail: kturaga@gmail.com collates some of the remarkable work presented at the International Symposium of Regional Therapies, in Snow Bird, Utah 2017.

The first two articles examine appendiceal epithelial neoplasms (AENs) with peritoneal dissemination and an attempt to validate the Peritoneal Surface Oncology Group International (PSOGI) classification of AEN. Baratti et al. ${ }^{1}$ examined 265 patients with mucinous peritoneal disease and found that the 10 years survival rate for patients with acellular mucin was $90 \%, 63 \%$ for low-grade disease, $40 \%$ for high-grade disease, and $0 \%$ for signet ring cell disease. Similarly, after examining 310 patients, Choudry et al., ${ }^{2}$ found that the 5-year progression-free survival rate was $100 \%$ for patients with acellular mucin, $83 \%$ for those with scant cellularity, and only $27 \%$ for those with moderate cellularity. Although these articles corroborate the discrimination of the new classification, they point to the importance of cellularity in the extra-appendiceal mucin.

Extra-appendiceal epithelial cells have been suggested to indicate a high risk of recurrence. Guaglio et al. ${ }^{3}$ present a prospective series that challenges this paradigm and suggest that any low-grade appendiceal neoplasm (LAMN) with pelvic or right lower quadrant acellular mucin or cells can be treated with a radical appendectomy. They also suggest that this group of patients might not have a high risk of recurrence and can be safely surveilled. Although these data are intriguing, larger and longer series are necessary to define the risk of recurrence better.

The technique for the delivery of hyperthermic intraperitoneal chemotherapy (HIPEC) has been understudied, and this series includes four articles that attempt to understand several physiologic components of the technique and its effects on the host. Franko et al. ${ }^{4}$ identify antimicrobial properties of the perfusate, whereas Stewart 
et al. ${ }^{5}$ question the value of dextrose containing perfusate carrier due to deleterious hyperglycemia. The association of core body temperature in predicting postoperative complications is suggested by Goldenshuger et al. ${ }^{6}$ after examination of outcomes for 115 patients. In addition, Feferman et al. ${ }^{7}$ question the role of routine granulocytemacrophage colony-stimulating factor (GM-CSF) support for patients undergoing intraperitoneal chemotherapy because their observed incidence of leukopenia was $7 \%$. Such investigations are critical to advancing our understanding of the technique's components.

Cytoreductive surgery and HIPEC can have significant morbidity for patients, and the next few articles explore several factors that predict the morbidity of the surgery. Not surprisingly, Chouliaras et al. ${ }^{8}$ find that preoperative frailty correlates with significant morbidity and mortality (grade 4 morbidity, $7 \%$ [non-frail] vs 33\% [severely frail]). In addition, Kelly et al. ${ }^{9}$ found that patients with a high Charlson Comorbidity Index and stoma creation were at a high risk for 60-day readmissions, which occurred for $17 \%$ of all patients. Further highlighting this important issue, Choudry et al. ${ }^{10}$ found that $34 \%$ of 1435 patients undergoing CRS + HIPEC had ostomies, which were reversed $82 \%$ of the time if they had loop ileostomies, but almost never $(<10 \%)$ if they did not. This is consistent with previously reported data showing that a stoma creation is not without morbidity for such patients and that a significant risk of non-reversal remains.

Votanopoulos et al. ${ }^{11}$ and Kluger et al. ${ }^{12}$ present some intriguing work on the management of peritoneal mesothelioma. The former reports from the PSOGI registry on favorable outcomes for patients who have low-volume biphasic mesothelioma with complete cytoreduction, which is sometimes considered a contraindication to surgery. Kluger et al. ${ }^{12}$ present a unique but an effective two-stage cytoreduction and heated intraperitoneal chemotherapy protocol for patients with mesothelioma, demonstrating favorable recurrence-free survival in this otherwise difficult histology.

In an attempt to understand the effects of regional therapies on aggressive histologies, the next four articles explore the role of this therapy for desmoplastic round cell tumors, high-grade appendiceal endometrial carcinoma, and multifocal cholangiocarcinoma. ${ }^{13-15}$ While noting the aggressiveness of histologies, the first three articles show a common theme, that a complete cytoreduction results in favorable recurrence-free and overall survival. Interestingly, although the Peritoneal Cancer Index (PCI) score was predictive of ability to cytoreduce, it did not predict survival for patients with high-grade appendiceal or endometrial carcinoma. Wright et al. ${ }^{16}$ describe the outcomes of intraarterial therapy (transarterial chemoembolization [TACE], transarterial radioembolization [TARE], and hepatic arterial infusion [HAI]) for patients with multifocal cholangiocarcinomas, which were similar to the outcomes for patients undergoing surgical resection despite the obvious selection bias.

In this supplement, we also include one of the largest ever analysis of patients undergoing isolated limb infusions. The report describes experiences of the Moffitt Cancer Center ${ }^{17}$ with 205 isolated limb infusions, which can be studied alongside results of 150 infusions from the Peking University Medical Center showing slightly lower response rates in an Asian population. ${ }^{18}$ In addition, a meta-analysis on the role of isolated limb infusion (ILI) for sarcomas presented by Neuwirth et al. ${ }^{19}$ demonstrates a complete response rate of $26 \%$. This comprehensive analysis of regional therapies used for the limb is the result of collaboration, science, and persistent efforts at centers of excellence.

During the last several years, advances in the field of regional therapies have occurred due to teams of people working together, and this supplement is a result of collaborative work from researchers, physicians, health care providers, and patients. We hope to see you at Jacksonville in 2018 and create better ways to work together.

\section{REFERENCES}

1. Baratti D, Usamura S, Milione M, Bruno F, Guaglio M, Deraco M. Validation of the recent PSOGI pathological classification of pseudomyxoma peritonei in a single-center series of 265 patients treated by cytoreductive surgery and hyperthermic intraperitoneal chemotherapy. Ann Surg Oncol. 2018. https://doi.org/10.1245/s 10434-017-6252-1.

2. Choudry H, Pai R, Shuai Y, Ramalingam L, Jones H, Pingpank J, et al. Impact of cellularity on oncologic outcomes following cytoreductive surgery and hyperthermic intraperitoneal chemoperfusion for pseudomyxoma peritonei. Ann Surg Oncol. 2018. h ttps://doi.org/10.1245/s10434-017-6214-7.

3. Guaglio M, Sinukumar S, Kusamura S, Milione M, Pietrantonio F, Battaglia L, et al. Clinical surveillance after macroscopically complete surgery for low-grade appendiceal mucinous neoplasms (LAMN) with or without limited peritoneal spread: long-term results in a prospective series. Ann Surg Oncol. 2017. https://doi. org/10.1245/s10434-017-6305-5.

4. Franko J, Lange KN, McKay D, Gentry BG. Antimicrobial properties of perfusate fluid after cytoreductive surgery and hyperthermic intraperitoneal chemotherapy (CS-HIPEC) with mitomycin C. Ann Surg Oncol. 2017. https://doi.org/10.1245/s1 0434-017-6113-y.

5. Stewart C, Gleisner A, Halpern A, Ibrahim-Zada I, Luna R, Pearlman $\mathrm{N}$, et al. Implications of hyperthermic intraperitoneal chemotherapy perfusion-related hyperglycemia. Ann Surg Oncol. 2017. https://doi.org/10.1245/s10434-017-6284-6.

6. Rayman S, Mor E, Berkenstadt H, Fogel-Grinvald H, Venturero $\mathrm{M}$, Nissan A. Core body temperature but not intraabdominal pressure predicts postoperative complications following closedsystem hyperthermic intraperitoneal chemotherapy (HIPEC) administration. Ann Surg Oncol. 2017. https://doi.org/10.1245/ s10434-017-6279-3. 
7. Feferman Y, Bhagwandin S, Kim J, Aycart S, Feingold D, Labow D, Sarpel U. Conflicting data on the incidence of leukopenia and neutropenia after heated intraperitoneal chemotherapy with mitomycin C. Ann Surg Oncol. 2017. https://doi.org/10.1245/ s10434-017-6112-z.

8. Chouliaras K, Konstantinidis I, Levine E, Lee B, Votanopoulos K. Frailty correlates with postoperative mortality and major morbidity after cytoreductive surgery with hyperthermic intraperitoneal chemotherapy. Ann Surg Oncol. 2017. https://doi. org/10.1245/s10434-017-6111-0.

9. Kelly K, Cajas-Monson L, Baumgartner Joel, Lowy A. Factors associated with 60-day readmission following cytoreduction and hyperthermic intraperitoneal chemotherapy. Ann Surg Oncol. 2018. https://doi.org/10.1245/s10434-017-6108-8.

10. Choudry H, Pakrafter S, Shuai Y, Ramalingam L, Jones H, Pingpank J, et al. Institutional experience with ostomies created during cytoreductive surgery and hyperthermic intraperitoneal chemoperfusion. Ann Surg Oncol. 2017. https://doi.org/10.1245/ s10434-017-6114-x.

11. Chouliaras K, Votanopoulos K, Sugarbaker P, Deraco M, Morris $\mathrm{D}$, Glehen $\mathrm{O}$, et al. Is cytoreductive surgery with hyperthermic intraperitoneal chemotherapy justified for biphasic variants of peritoneal mesothelioma? Outcomes from the Peritoneal Surface Oncology Group International Registry. Ann Surg Oncol. 2017. h ttps://doi.org/10.1245/s10434-017-6293-5.

12. Kluger M, Heller D, Chiuzan C, Taub R, Leinwand J, Greene A, et al. Recurrence of optimally treated malignant peritoneal mesothelioma with cytoreduction and heated intraperitoneal chemotherapy. Ann Surg Oncol. 2017. https://doi.org/10.1245/s 10434-017-6106-x

13. Hayes-Jordan A (proxy) (contact), Coakley B, Green H, Xiao L, Fournier K, Herzog C, et al. Desmoplastic small round cell tumor treated with cytoreductive surgery and hyperthermic intraperitoneal chemotherapy: results of a phase 2 trial. Ann Surg Oncol. 2018. In press.

14. Chouliaras K (proxy) (contact), Votanopoulos K, Bartlett D, Moran B, Choudry H, Russell G, et al. PCI is not predictive of survival after complete CRS/HIPEC in peritoneal dissemination from high-grade appendiceal primaries. Ann Surg Oncol. 2018. In press.

15. Sammartino $P$ (proxy) (contact), Cornali $T$, Kopanakis $N$, Christopoulou A, Framarino dei Malatesta M, Efstathiou E, Sammartino P, Kopaanakis N, et al. Cytoreductive surgery plus hyperthermic intraperitoneal chemotherapy for patients with peritoneal metastases from endometrial cancer. Ann Surg Oncol. 2018. In press.

16. Wright GP, Perkins S, Jones H, Zureikat A, Marsh J, Holtzman $M$, et al. Surgical resection does not improve survival in multifocal intrahepatic cholangiocarcinoma: a comparison of surgical resection with intra-arterial therapies. Ann Surg Oncol. 2018. h ttps://doi.org/10.1245/s10434-017-6110-1.

17. O’Donoghue C, Perez M, Mullinax J, Hardman D, Sileno S, Naqvi S, et al. Isolated limb infusion: a single-center experience with over 200 infusions. Ann Surg Oncol. 2017. https://doi.org/ 10.1245/s10434-017-6107-9.

18. Siming L, Xinan S, Lu Si, et al. Outcomes and predictive factors of isolated limb infusion for patients with in-transit melanoma in China. Ann Surg Oncol. 2017. https://doi.org/10.1245/s10434-0 17-6256-x. In press.

19. Neuwirth M, Song Y, Sinnamon A, Fraker D, Zager J, Karakousis G. solated limb perfusion and infusion for extremity soft tissue sarcoma: a contemporary systematic review and meta-analysis. Ann Surg Oncol. 2017. https://doi.org/10.1245/s10434-017-61097. 